\title{
REUNIÓN RED DE ESCUELAS DE SALUD PÚBLICA DE UNASUR
}

\author{
Recent meeting of the schools of Public Health Network \\ of the Union of South American Nations (Unasur)
}

Entre los días 10 y 12 de diciembre de 2014, se desarrolló en Chile la Tercera Reunión de la Red de Escuelas de Salud Pública de la Unión de Naciones Suramericanas y que tuvo como objetivo abordar el tema de desafíos de formación en Salud Pública en la región.

Para comprender la importancia de esta instancia conviene entender primero qué es UNASUR y cómo se inserta la Red de Escuelas de Salud Pública en esta organización.

La Unión de Naciones Suramericanas (UNASUR) es un organismo internacional, cuyo tratado constitutivo fue aprobado en Brasilia el 23 de mayo de 2008, que está conformado por cada uno de los doce países suramericanos, es decir, Argentina, Bolivia, Brasil, Colombia, Chile, Ecuador, Guyana, Paraguay, Perú, Suriname, Uruguay y Venezuela. El objetivo principal de esta organización es construir un espacio de integración político, económico, social y cultural, que respete la diversidad de las realidades de cada país. Entre los desafíos más relevantes que plantea UNASUR, se pueden señalar la eliminación de las desigualdades socioeconómicas, alcanzar la inclusión social, aumentar la participación ciudadana y fortalecer la democracia, considerando la soberanía e independencia de los Estados. Los órganos institucionales de UNASUR son el Consejo de Jefas y Jefes de Estado y de Gobierno, Consejo de Ministras y Ministros de Relaciones Exteriores, Consejo de Delegadas y Delegados, y Secretaría General. Existe una Presidencia Pro Tempore de UNASUR, que es ejercida en forma sucesiva por cada uno de los Estados Miembros, por períodos anuales.

La organización del quehacer funcional de UNASUR descansa en doce Consejos que trabajan en diferentes áreas, una de las cuales corresponde a salud. El Consejo de Salud Suramericano (UNASUR Salud) es una instancia permanente, formada por los ministros y ministras de Salud de los países que conforman UNASUR. La Presidencia del Consejo de Salud corresponde a la ministra o ministro de Salud del mismo país que ocupa la Presidencia Pro Tempore de UNASUR. A su vez, el Consejo de Salud Suramericano tiene grupos técnicos por áreas de trabajo definidas por el propio Consejo, a los que se integran los países que deseen formar parte de ellos, con una coordinación a cargo de un país, a modo de Secretaría Ejecutiva. La Red de Escuelas de Salud Pública (RESP/UNASUR) es uno

Óscar Arteaga Director Escuela de Salud Pública Universidad de Chile de estos grupos técnicos; existe también la Red de Institutos Nacionales de Salud (RINS/UNASUR), la Red de Escuelas Técnicas de Salud y el Instituto Suramericano de Gobierno en Salud (ISAGS), entre otros. 
La RESP/UNASUR tiene por objetivo contribuir al desarrollo de políticas orientadas a la formación de recursos humanos para hacer frente a los desafíos de salud de la región, promoviendo la mejor gobernanza de los procesos de formación de recursos humanos para la salud a través de vínculos entre las Escuelas de Salud Pública, Escuelas de Gobierno y Ministerios de Salud de la región. La Escuela Nacional de Salud Pública de la Fundación Oswaldo Cruz (Fiocruz) ejerce la Secretaría Ejecutiva de la RESP/UNASUR: por su parte la Escuela de Salud Pública de la Universidad de Chile (ESP UChile) representa a las instituciones chilenas formadoras en Salud Pública por nombramiento del Ministerio de Salud de Chile.

En la mencionada Tercera Reunión de la RESP/UNASUR de diciembre pasado, se abordaron temas relevantes como la institucionalización de la Red a través de la aprobación de un reglamento para regular su funcionamiento, se compartieron experiencias en relación con la formación de recursos humanos en Salud Pública entre los países participantes y se estableció un plan de trabajo, con un cronograma de ejecución y responsabilidades de los Estados en su ejecución para los próximos dos años.

El desarrollo de esta Tercera Reunión de la RESP/UNASUR en Chile también permitió que se pudieran integrar al trabajo las universidades que conforman la Red Chilena de Instituciones Formadoras en Salud Pública, instancia a cuya creación convocó en 2011 la ESP UChile y de la cual ésta ejerce la Secretaría Ejecutiva.

Quizá para muchas personas, la participación en instancias internacionales sea algo ajeno o lejano. Sin embargo, en un mundo en el que los procesos de globalización han ido avanzando hasta niveles que hoy cuestionan las nociones tradicionales de Estado-nación, un escenario en el que las personas, los bienes y servicios se mueven sin consideraciones de las fronteras físicas de los países, un mundo en el que las tecnologías de comunicación posibilitan las mutuas influencias sociales y culturales entre pueblos diversos, lo que ocurra en el ámbito de los organismos internacionales es muy relevante.

En materia de recursos humanos para salud, los fenómenos de creciente integración regional en América del Sur, como la propia UNASUR o las iniciativas de integración económica como MERCOSUR o en su momento el Pacto Andino, seguramente nos irán conduciendo a una situación como la que existe hace años en Europa, en la que las personas obtienen su título profesional en un país y pueden ejercer libremente en cualquier otro. ¿Estamos preparados para enfrentar situaciones como ésta? ¿Estamos siquiera pensando en cómo enfrentar los desafíos que nos plantean situaciones de salud que son comunes a los países de la región suramericana? ¿O cómo organizar nuestros servicios de salud para ir alcanzando metas compartidas de cobertura universal en nuestros países?

Instancias como RESP/UNASUR constituyen una oportunidad para estas reflexiones, con el propósito de ir alimentando políticas públicas que aborden estos problemas. Por esta razón, la ESP UChile ha destinado energías y esfuerzos en participar de manera activa y protagónica en estas instancias, así como en la construcción de redes nacionales e internacionales para ir generando las sinergias que nos permitan fortalecer la cooperación interinstitucional; que nos permitan, en definitiva, cambiar las lógicas de competencia que han dominado nuestras relaciones institucionales por lógicas de colaboración. Estamos convencidos de que ése es el camino para fortalecer la cohesión social y contribuir a hacer de nuestros países sociedades más justas. 